\title{
Lead and Zinc Research
}

\author{
by Schrade F. Radtke of the American Zinc Institute \& the Lead Industries Assn.
}

The lead and zinc industries of the US, Canada, England, Australia, South America, and Africa-through the Expanded Research Program of the American Zinc Institute and the Lead Industries Association-have undertaken a major research effort to develop new uses for lead and zinc, backed up by extensive fundamental research.

Although the program has been under way for only a few years, significant results have been achieved. Research at the Battelle Memorial Institute, devoted to new plating processes for automotive zinc die castings has shown that duplex nickel over conventional copper, followed by bright, crack-free chromium, results in a plating system far superior to conventional practices-which can no longer withstand the severe corrosive conditions encountered on today's highways. This new system has important applications for appliance and marine hardware, as shown by exposure tests.

A new titanium-copper zinc-base alloy has broad application for architectural markets. For lithographic plate, its resistance to creep and its adaptability to lithographic plate preparation promises recovery of zinc's former position. The Lithographic Technical Foundation has developed new graining and wipe-on diazo treatments for this alloy which will enhance zinc's technical merits.

A cooperative effort with the John F. Robertson Co. has led to the development of a new press for the continuous extrusion of lead cable sheathing alloys. For the first time, it has been possible to extrude continuously the arsenical alloys, tellurium-bearing lead, and antimonial lead. Heretofore, only commerciallypure and copper-bearing lead have been extruded continuously. Not only will cost reductions be possible in continuous extrusion, but a metallurgically superior product can be produced, and plastic insulating materials can be employed as well.

At Rutgers University a fundamental investigation of ceramic dielectric materials employing lead additives has resulted in the development of an ultra-low-loss dielectric material superior to anything known previously. This is only one of 11 fellowships covering the utili- zation of lead in ceramics, glasses, glazes, ferroelectrics, and thermal and spectral emissive materials. A corresponding program is being initiated for zinc.

The incorporation of galvanized steel in the underbody portions of unitized automobile bodies promises to yield a vital, new market for zinc. While significant advances have been made in resistance welding steel, satisfactory electrode life for mass production lines remains to be achieved. An important welding program has been started at The Budd Co. to assist in developing welding electrodes and welding practices to meet production line requirements.

The New Jersey Zinc Co. has under investigation new die casting alloys for the hot chamber prócess in the range of 5 to 18 pct Al. The principal objective is to achieve materials with superior physical properties and castability.

Rensselaer Polytechnic Institute is conducting fundamental investigation of the powder metallurgy process for producing wrought alloys directly from powders. Initial results have shown that superior properties can be obtained by naturallyoccurring oxide films on the particles together with fine-grained material showing nondirectional properties. In the lead system, a 5 pct $\mathrm{Cu}$ alloy atomized and air-quenched has yielded ultimate tensile strengths in the range of $8000+$ psi and elongations of over 15 pet.

Other dramatic property improvements, accompanied by significant increases in resistance to creep, have been obtained through the use of fiber mat reinforcement of lead. This research, together with a vital study of lead-base alloys, is being undertaken at Armour Research Foundation. This latter study, incorporating lead of 99.9999 pct purity, has caused a reassessment of prior literature. Alloying elements added in thousandths of a percent produce major changes in physical properties and point the way toward the development of improved lead alloys.

Because of lead's high density and low modulus, it has inherently excellent characteristics for attenuating sound and vibration. Composite pads of lead and asbestos have been used for years in attenuating vibra- tions from railroad beds in building structures, but complete engineering data required for exploitation of related markets were unavailable, hence the initiation of a major program to develop attenuation characteristics of lead as a function of frequency and unit loading.

In sound, lead incorporated in plastic sheeting has been used to attenuate sound in the DC-8 jet transport and other aircraft. The potential for architectural applications in sound-impervious drapes, building partitions, doors, and wallpaper is great, hence the initiation of a major program to design typical components together with data on the economic and acoustical efficiency of such end items.

Lead and zinc are most often employed where their corrosion resistance characteristics become a major factor in performance. Therefore, their behavior is influenced predominantly by the characteristics of their surfaces. In lead, research has been started at the University of Melbourne on the chemical and metallurgical behavior of the lead surface as a function of atmospheres, corrosive media, the influence of alloying constituents, and temperature. A similar program will be undertaken by the British Non-Ferrous Metals Research Association.

The market for lead tetraethyl is of major significance, yet it is the only major market for lead chemicals outside of the paint and pigment industry. Because of the chemical industry's challenge, three programs of significance have been initiated: one with T.N.O. in Utrecht, Holland another with the Quartermaster Research and Engineering Command of the US Army, and a third with Arthur D. Little Inc. The first two programs cover fundamental research in lead organometallics, the study and synthesis of new lead organometallics. The Arthur D. Little program will take existing lead chemicals, plus the products of the two fundamental programs, and evaluate their application for plastic intermediates for their biological activity, etc.

These are but a few of the many new developments in lead and zinc leading to a growing demand for the metals and an ever increasing need in our present-day technology. 